\title{
Michael Kessler
}

When the University of Houston decided to reconstitute its Foreign Languages Laboratory operation, it invested in a cassette laboratory, a six slave high speed duplicator, 3000 sixty-minute cassettes, and 1200 soft plastic cases, and assumed that the cassettes would be lent out to students on a take-home basis. Thus the new laboratory had to be organized not only as a listening laboratory, but also as a cassette library service arranged so as to facilitate a take-home service. For the last three years, the laboratory has operated a successful take-home service, disproving all the dire predictions about a tape inventory that would disappear in one semester.

At the moment, the laboratory has an inventory of 3610 tapes, categorized as follows:

957 are in storage

679 are masters used only for duplicating

652 are laboratory copies to be used only in the laboratory

974 are in circulation

335 are outstanding

13 are unaccounted for

These figures represent the tape inventory for Fall 1979, and while there may be changes here and there because of programs being deleted from the system and new ones placed on file, the figures have remained fairly constant over the last two years. The laboratory cycles approximately 1,000 tapes in a semester, with a lend out rate of 5,564 (again using Fall 1979 figures). Assuming a 5,000 copies lending rate in each regular semester (lab use and tape borrowing usually decreases in the Spring), 25,000 copies were lent out since Fall 1977 with an outside loss of 348 tapes. Students may borrow a maximum of 3 tapes at any given time. Any increase in the number of tapes borrowed or any change in the length of the take-out period would change the frequency of borrowing and the number of tapes needed in the inventory.

To operate the take-home service successfully, it was decided that some deterrent had to be applied so that students would not forget their tapes permanently A student who loses a tape must pay four dollars for it or replace it with a brand new tape that is approved by the laboratory. The figure of four dollars is purely arbitrary, and the laboratory does not hide the fact from any person who asks about it. It was felt that charging the replacement cost of the tape (anywhere from $44 \mathrm{c}$ to $88 \mathrm{c}$ per tape on a bulk basis) constituted an insufficient deterrent and would lead to tremendous losses because of students who would wish to keep a copy of all their lessons for review purposes. Moreover, the tapes could be erased and become a cheap way of acquiring tapes for personal use for anything but a demanding reproduction of high fidelity. The laboratory does not keep any money collected for fines or lost tapes, but by levying a fairly high replacement fee the laboratory is more likely to receive a tape in return that becomes part of its inventory. 
If a student is late with a tape, a fine of $20 \mathrm{c}$ per day per tape up to the replacement cost of the tape will be assessed. On the other hand, no charge is levied for tapes that are damaged on the theory that the damage is often repairable, and we want to encourage students to return tapes no matter what. Delinquent accounts, i.e. more than 20 days late on tapes or money owed, have financial stops placed against them through the university records.

Students have the habit of coming into the laboratory in the ten minutes they might have between classes, and expect to receive a tape in that limited time. A system must be devised that will allow the lab assistants to distribute tapes as quickly as possible with as little error as possible. The tapes have been given an identification which include a color code for the department, a number code for the language, a letter code for the series, and then a sequential code for each tape in the series. The laboratory services three departments (French, German and Spanish), so there are three colors used in identifying tapes. The Spanish department includes the other 8 "minor" foreign languages taught at the university, so that its color may have any of 9 numbers following it. For example, a tape in Hebrew Literature, which is a tape of the instructor's lectures, will be coded red (that is the color of the Spanish department), then numbered 8 (it was the eighth language placed in the lab's files), identified as LAU (these are the first three letters of the instructor's last name) and then numbered 01 through however many tapes are used to record the lectures (each tape contains two numbers representing two sides of the tape). ${ }^{2}$ Thus the fifth lecture will be identified as follows: 8 Lau/ 09 \& 10 preceded by a red mark. The master of that tape is labeled 8 Lau/ $09 \&$ $10 \mathrm{M}$. If the instructor did not want students to listen to that tape, the master would be labeled $8 \mathrm{Lau} / 09$ \& $10 \mathrm{MX}$. If he insisted that the students may not take the tape home but should listen to it only in the lab, the master would be labeled 8 Lau/ $09 \& 10 \mathrm{ML}$. Thus any identifying let'er on the master after the $M$ means that no take-home copies can be made of that tape. ${ }^{3}$

It is important to follow the logic of the numbering even if lessons do not abide by it totally. For example, if a series of tapes has one lesson per side, and then one of the lessons is more than 30 minutes long, then the lesson will take two sides and the subsequent lessons will no longer correspond in number to the tape sides. Side 01 can contain lesson 1, 02 lesson 2, 03 \& 04 lesson 3, 05 lesson 4 and so on. In fact, most of the time, lesson one will not be on the first side because basic language programs usually begin with proninciation exercises and other introductory materials. We also feel that a lesson should not be split between two tapes if at all possible, and this might result in blank sides, so that a series might run this way:

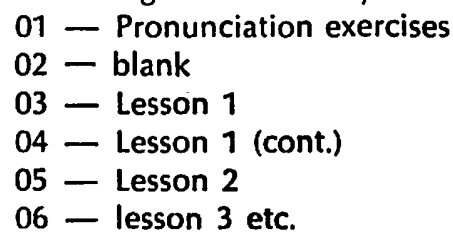


The idea behind the system is to create an order that will apply to any tape series regardless of its contents so that all the tapes may be easily found. A student needing a tape simply has to state the name of the author and the lesson number, and the proper tape will be provided in a very short time. After a while the lab assistants know which tapes correspond to which lessons, but even if they do not know, they can simply look them up in the card file (also color coded) that is kept in the laboratory, listing all the tapes under the author's name or its principal speaker if that is more appropriate.

Although we have three distinct locations to separate the three varieties of tapes-master, lab use only and general circulation-the three varieties correspond to each other in code, and finding a tape is very easy. Wherever one may be looking for a tape, be it in the master file, in the file for lab copies or on the shelves for take-home copies, color becomes the first identifying element, followed by the language code and so on down to the smallest detail needed to issue the proper tape to the student.

Since the laboratory will duplicate and distribute as many copies as are needed for any given program, the tapes are identified by means of removable spine labels; and it is obvious that the laboratory cannot use the traditional library system of having a card for each tape that is distributed. The system devised was one which reversed the identification method by having a card on each person who takes out a tape. The card identifies the student by name and student number, and all transactions pertaining to that student will be marked down on the card. The card looks as follows, with the back having the same divisions but no space for the name and student number:

Name :

Last name

First name

In1t1al

Te1. No.:

Student No.

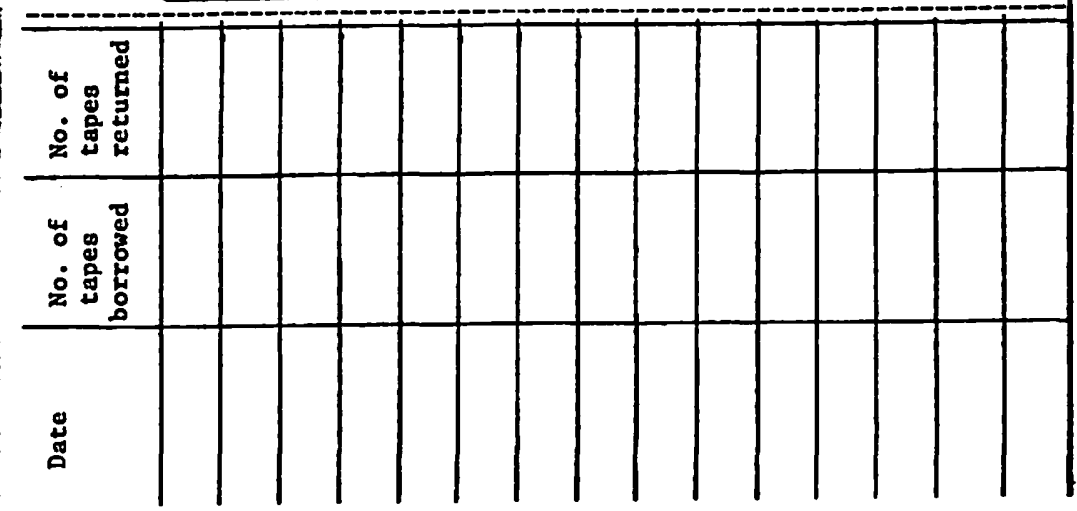


Whenever a student checks out a tape to take home, his card is pulled from the file and stamped with the current date. The number of tapes he checks out is marked in the Tapes Borrowed column. Should he already have tapes in his possession, these tapes are automatically renewed by marking down their return in the Tapes Returned column and their being checked out in the Tapes Borrowed column. The reason for this procedure is to keep information simple and up to date. The last line on the card will always be the finalized account. There will be no need to backtrack, and errors are therefore reduced. If the card were to read as follows, it would not be possible to tell whether an error was committed and the student had only two tapes in his possession, or if he had three tapes altogether:

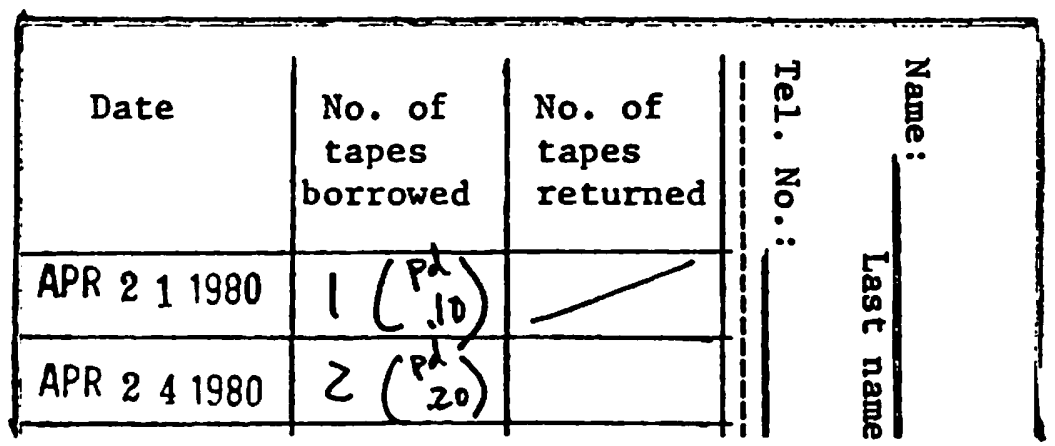

If the card were marked in the following manner, whether the student actually returned a tape or asked to renew one, which is just a bookkeeping procedure (we accept telephone renewals but count Sundays even though the lab is closed that day), then the final entry would be the only one to look at the next time:

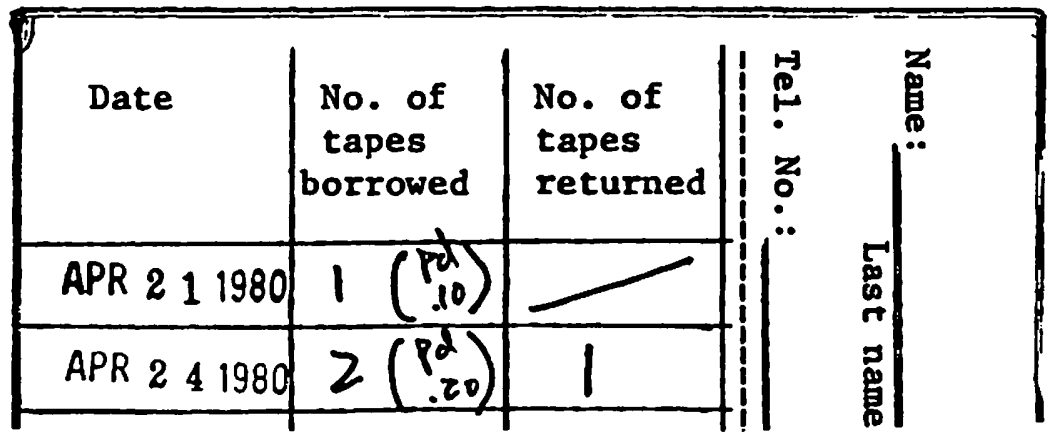

For a while there were occasional instances when the system did not work, and students would claim that they had returned tapes when it was not marked down on the card (students are warned in a handout sheet that it is their responsibility to make sure that the card is correct), often because the lab assistant would inadvertently mark down both columns with the number of tapes returned. In January 1979, the lab started charging a use fee for tapes taken home, and this resolved any remaining problems. In the space next to the number of tapes borrowed, 
the lab assistant had to mark down either the amount paid (10c per tape for a week's borrowing) or the amount owed if the student did not happen to have the money that day or renewed the tape(s) by telephone. In addition, any fine paid had to be not only marked down in the Tapes Returned column, but also signed for on a separate sheet of paper. The use fee and the fines go into separate accounts, and it is only by subtracting the fine from the total amount in the cash box that the amount taken as a use fee could be established. Now, if a student returns a tape, a minimum of two transactions must take place (stamping the date and marking the Tape Returned column) and if he or she is borrowing a tape, another two transactions must take place (marking the Tapes Borrowed column and writing in the amount paid), and it is much less likely that any errors will be made. Moreover, if errors are made, they usually are very obvious because they do not conform to the normal pattern found on the other cards.

The success of the system has been proven by the results. The laboratory has managed to operate essentially with part-time student help without difficulty. While the explanation may appear complicated, the operation itself has been reduced to the simplest system possible to distribute as many tapes as possible with as little error as possible.

\section{Footnotes}

'Anyone familiar with the book will recognize the obvious influence of Edward M. Stack's The Language Laboratory and Modern Language Teaching, Third Edition, Oxford University Press, London, 1971.

2It should be noted that the letter code identifies a program, and if an author should have more than one program to his name, a different letter code would have to be devised for each program, and preferably letter codes which keep them far apart in the cassette files.

3The lab has a policy that no program that is copyrighted shall be duplicated without first obtaining a release from the publisher.

Michael Kessler

College of Humanities \& Fine Arts

University of Houston

Houston, Texas 77004 